\title{
Physicochemical Stability of Poly(lactide-co-glycolide) Nanocapsules Containing the Local Anesthetic Bupivacaine
}

\author{
Carolina M. Moraes, ${ }^{a}$ Eneida de Paula, ${ }^{a}$ André H. Rosa ${ }^{b}$ and \\ Leonardo F. Fraceto $*$,a,b \\ aInstituto de Biologia, Universidade Estadual de Campinas, Cidade Universitária "Zeferino Vaz", \\ 13083-970 Campinas-SP, Brazil \\ ${ }^{b}$ Departamento de Engenharia Ambiental, Universidade Estadual Paulista Júlio de Mesquita Filho, \\ Av. Três de Março, 511, 18087-180 Sorocaba-SP, Brazil
}

\begin{abstract}
Neste trabalho foi realizada a preparação de nanocápsulas de poli (DL-lactídeo-co-glicolídeo) (PLGA) como um sistema carreador para o anestésico local bupivacaína. A preparação foi caracterizada e sua estabilidade físico-química avaliada. Os resultados da caracterização mostram uma distribuição de tamanho com um índice de polidispersão de 0,12 , um diâmetro médio de $148 \mathrm{~nm}$, um potencial zeta de $-43,5 \mathrm{mV}$ e uma eficiência de associação da BVC nas nanocápsulas de $75,8 \%$. As propriedades físico-químicas das suspensões (diâmetro hidrodinâmico, índice de polidispersão, potencial zeta e eficiência de associação do fármaco) contendo nanocápsulas poliméricas foram avaliadas em função do tempo a fim de determinar sua estabilidade. Nenhuma grande alteração foi observada em função tempo para as suspensões de nanocápsulas avaliadas, sendo consideradas estáveis por um período de armazenagem de 120 dias a temperatura ambiente. Os resultados aqui apresentados, os quais se referem ao estudo desta nova formulação para anestésico local bupivacaína mostram-se promissores para futuros estudos in vivo.
\end{abstract}

This paper describes the preparation of poly(DL-lactide-co-glicolide) (PLGA) nanocapsules as a drug carrier system for the local anesthetic bupivacaine. The system was characterized and its stability investigated. The results showed a size distribution with a polydispersity index of 0.12 , an average diameter of $148 \mathrm{~nm}$, a zeta potential of $-43.5 \mathrm{mV}$ and an entrapment efficiency of $75.8 \%$. The physicochemical properties of polymeric nanocapsule suspensions (average diameter, polydispersity, zeta potential and drug association efficiency) were evaluated as a function of time to determine the formulation stability. The formulation did not display major changes in these properties over the time, and it was considered stable up to 120 days of storage at room temperature. The results reported here which refer to the initial characterization of these new formulations for the local anesthetic bupivacaine show a promising potential for future in vivo studies. stability

Keywords: bupivacaine, local anesthetic, polymeric nanocapsules, PLGA, physical-chemical

\section{Introduction}

Numerous studies today are focusing on the development of new pharmaceutical formulations based on nanocarriers, which have demonstrated several advantages over conventional formulations, making this research line a promising and innovative area of the pharmaceutical sector.,

Polymer nanoparticles (PN) are carriers of drugs or other active molecules whose sizes range from 10 to $1000 \mathrm{~nm}$.

\footnotetext{
*e-mail: leonardo@sorocaba.unesp.br
}

Nanospheres (NS) or nanocapsules (NC) can be obtained, depending on the method of preparation and the materials employed. NC consists of a polymer casing and a nucleus (usually oily). The drug inside the NC may be dissolved in the oily nucleus or adsorbed on the polymeric wall. NS, on the other hand, consists of a polymer matrix and their composition does not include oil. In this system, the drug may be adsorbed or dispersed in the polymeric matrix. ${ }^{2-6}$

Several polymers are used in the preparation of NS or $\mathrm{NC}$; however, aliphatic polyesters are the most attractive for injectable systems due to their biodegradability, availability, 
biocompatibility, absence of toxicity and because they are easy to incorporate into a wide range of drugs. ${ }^{7}$ The degradation of aliphatic polyesters may result from the enzymatic action and/or hydrolysis of the ester bond and may be affected by the properties of these polymers, such as their chemical composition, molar mass, solubility, hydrophobicity/hydrophilicity, transition temperature, structure (crystalline or amorphous), among other factors. ${ }^{8,9}$

The aliphatic polyesters most commonly used are poly(lactic acid) (PLA), poly(glycolic acid) (PGA), poly(lactic-co-glycolic acid) (PLGA), poly ( $\varepsilon$-caprolactone) (PCL), poly(hydroxyvalerate) (PHV) and poly(hydroxybutyrate) (PHB).,10

Local anesthetics (LA) are molecules whose primary pharmacological activity involves reversible nerve conduction blockage. ${ }^{11,12}$ Although several physicochemical models have been proposed to explain how LA block nerve conduction, the principal mechanism involves its interaction at one or more specific sites in the sodiumdependent channels of neural membranes. ${ }^{13-15}$

Bupivacaine (BVC) is a LA of the amino amide class, which, together with two other LA of this class, lidocaine and ropivacaine, are the drugs of choice in acute and chronic pain therapy. Bupivacaine is commercially available in formulations varying from 0.25 to $0.75 \%$ in mass of BVC..$^{16,17}$

Because the desirable characteristics for a LA include long duration of action, selectivity for sensory rather than motor nerve block and reduction of systemic toxicity, ${ }^{17,18}$ an alternative that has proved able to promote these desirable effects is the modified release of these drugs through carrier systems. The purpose of release systems is to promote slow and continuous release, reducing the systemic toxicity of these locally active drugs. ${ }^{17-19}$ Drug release systems are, in fact, able to compartmentalize the active substance and drive it to specific active sites, as well as control the rate of release without altering the chemical structure of the transported molecule. ${ }^{20}$

The delivery of local anesthetics, which has been studied extensively by many research groups and also by our laboratory, can be achieved by the formation of inclusion complexes with cyclodextrins, ${ }^{20-30}$ encapsulation in liposomes, ${ }^{31-39}$ association to polymer microparticles ${ }^{40-43}$ and association to polymeric nanostructured systems. ${ }^{44-48}$

The use of colloidal systems of polymeric nanoparticles is often limited due to problems of stability over long periods of time. A colloidal suspension does not normally show phase separation, since both sedimentation and aggregate formation are slow. However storage for many months can sometimes result in aggregation and consequently phase separation, which renders the use of such formulations nonviable. ${ }^{4}$ Hence, the purpose of this work was to prepare, characterize and monitor the physicochemical stability of PLGA nanocapsules containing bupivacaine. This study is important for the characterization of a new pharmaceutical form for pain therapy.

\section{Material and Methods}

The materials used were bupivacaine (free base, Cristália Ind. Farm. LTDA), poly(DL-lactide-co-glycolide, 50:50) (PLGA 50:50, MW 40,000-70,000 $\mathrm{g} \mathrm{mol}^{-1}$ ) (Sigma Aldrich Chem. Co.), sorbitan monostereate $\left(\mathrm{Span}^{\circ}{ }^{\circledR}\right)$ (Sigma Aldrich Chem. Co.), polysorbate 80 (Tween $80^{\circledR}$ ) (LabSynth, Brazil), caprylic/capric acid triglyceride (Miglyol 810 ${ }^{\circledR}$ ) (Hüls, Germany) and analytical grade acetone (LabSynth, Brazil). The solvents used for the chromatographic analyses were HPLC grade acetonitrile (JT Baker ${ }^{\circledR}$ ) and Milli-Q water.

Preparation of the PLGA nanocapsules with bupivacaine

The PLGA nanocapsules were prepared by the nanoprecipitation method, ${ }^{49}$ which involved mixing an organic phase in an aqueous phase. The organic phase consisted of PLA polymer $(100 \mathrm{mg})$, acetone $(30 \mathrm{~mL})$, bupivacaine $(25 \mathrm{mg})$, sorbitan monostereate $(40 \mathrm{mg})$ and caprylic/capric acid triglyceride $(200 \mathrm{mg})$. The aqueous phase was composed of polysorbate $80(60 \mathrm{mg})$ and deionized water $(30 \mathrm{~mL})$. After the dissolution of the components of both phases, the organic phase was gradually added to the aqueous phase using a small funnel. The resulting suspension was kept under agitation for $10 \mathrm{~min}$, after which it was concentrated under low pressure to a volume of $10 \mathrm{~mL}$, using a rotary evaporator, in order to obtain a suspension of bupivacaine with a concentration of $2.5 \mathrm{mg} \mathrm{mL}^{-1}$. A control formulation without bupivacaine was also prepared, following the methodology described above.

\section{Size and polydispersity measurements}

The dynamic light scattering technique was used to determine the mean particle size (hydrodynamic diameter) and polydispersity. These analyses were performed by diluting $(1: 1000, \mathrm{v} / \mathrm{v})$ the nanocapsule suspensions (with and without BVC) and using a ZetaPlus ${ }^{\oplus}$ particle analyzer with $90^{\circ}$ fixed angle detector, at a temperature of $25^{\circ} \mathrm{C}$. The size distribution and polydispersity were measured and were expressed as the mean of five determinations.

\section{Zeta potential measurements}

The value of the zeta potential, expressed in $\mathrm{mV}$, was determined using a ZetaPlus potential analyzer. 
The analyses were carried out by diluting $(1: 1000, \mathrm{v} / \mathrm{v})$ the nanocapsule suspensions (with and without BVC) in Milli-Q water, and the results were expressed as means of eight determinations.

\section{Efficiency of bupivacaine association in PLGA nanocapsules}

The percentage of BVC associated to the nanocapsules was determined by the ultrafiltration/centrifugation method. The nanocapsule samples containing bupivacaine were centrifuged in ultrafiltration filters composed of regenerated cellulose with $30 \mathrm{kDa}$ molecular sizeexclusion pores (Microcon-Millipore ${ }^{\circledR}$ ), and the filtrate was quantified by high performance liquid chromatography (HPLC). The concentration of BVC was determined using an analytical curve (concentration range: $1-200 \mu \mathrm{g} \mathrm{mL}^{-1}$, peak area $=3.30 \times 10^{5}[$ bupivacaine] + $4.7 \times 10^{5}, \mathrm{r}=0.9998, \mathrm{n}=6$ ). The specificity was tested in the presence of the colloidal suspension components, and it was demonstrated that these factors did not alter bupivacaine quantification.

The BVC association rate was determined from the difference between the drug concentration measured in the filtrate and its total concentration (100\%) in the nanocapsule suspension.

The chromatographic conditions employed in the quantification were: mobile phase composed of acetonitrile/phosphate buffer $\left(\mathrm{pH} 7.4,5 \mathrm{mmol} \mathrm{mL}^{-1}\right.$, i.e., $3 \mathrm{mmol} \mathrm{L}-1 \mathrm{Na}_{2} \mathrm{HPO}_{4}$ and $2 \mathrm{mmol} \mathrm{L} \mathrm{NaH}_{2} \mathrm{PO}_{4}$, $85: 15, \mathrm{v} / \mathrm{v}), 2.3 \mathrm{~mL} \mathrm{~min}^{-1}$ flow rate, and a Phenomenex Gemini chromatographic column $\left(\mathrm{C}_{18}\right.$ reversed phase, $5 \mu, 110 \AA, 150 \times 4.60 \mathrm{~mm})$. The $\mathrm{BVC}$ was detected at a wavelength of $220 \mathrm{~nm}$, using an ultraviolet (UV) detector. The injection volume was $20 \mu \mathrm{L}$ and all the injected samples were previously filtered through a $0.22 \mu \mathrm{mol} \mathrm{L}^{-1}$ polyethersulfone membrane (Millipore ${ }^{\circledR}$ ). The total BVC (100\%) in the PLGA nanocapsule suspension was determined by diluting the suspension in acetonitrile. Acetonitrile is able to dissolve the polymer, thus completely releasing the BVC which, in turn, was quantified based on the analytical curve validated by Resolution RE No. 899/2003 of ANVISA, Brazil's National Health Surveillance Agency.

\section{Colloidal stability measurements}

The stability of the PLGA NC suspensions containing BVC was evaluated upon determinations of size, polydispersity, zeta potential and association rate as a function of time (zero, 15, 60 and 120 days), with the suspensions stored in amber glass flasks at room temperature.

\section{Results and Discussion}

Measurements of the size (hydrodynamic diameter), polydispersity and zeta potential of particles are parameters that indicate the stability of nanocapsules in suspension. Table 1 lists the measured values of these parameters for the PLGA NC suspensions with BVC, as well as the association rate of this drug in the nanocapsules.

Table 1. Values of the mean diameter (hydrodynamic diameter, $\mathrm{nm}$ ), polydispersity, zeta potential $(\mathrm{mV})$ and association rate of the PLGA NC suspensions with BVC

\begin{tabular}{lc}
\hline Parameter & PGLA-NC: BVC \\
\hline Mean diameter $(\mathrm{nm})$ & 148 \\
Polydispersity & 0.12 \\
Association rate $(\%)$ & 75.8 \\
Zeta potential $(\mathrm{mV})$ & -43.5 \\
\hline
\end{tabular}

The results presented in Table 1 indicate that the PLGA NC suspensions with BVC presented a size (hydrodynamic diameter) and polydispersity compatible with colloidal suspensions. ${ }^{50}$ The zeta potential values of these formulations indicate good stability in solution, because they were lower than $-30 \mathrm{mV}$ and aggregation of particles in suspension was therefore avoided. ${ }^{4,5,52}$

The BVC association rate in the PLGA nanocapsules was $75.8 \%$, which is a very high value when compared to other studies reported in the literature for local anesthetics. ${ }^{44-48}$

The stabilities of the NC polymer suspensions containing BVC were evaluated based on the physicochemical properties of size, polydispersity, zeta potential and association efficiency as a function of time (initial, 15, 60 and 120 days), with all the samples stored in amber glass flasks at room temperature.

The graph in Figure 1(a) shows the particle size distribution by intensities obtained with the DTS nano software from light-scattering measurements of the PLGA $\mathrm{NC}$ containing BVC.

The results depicted in Figure 1(a) indicate that the size distribution in the formulation remained constant and unimodal for a period of 120 days, confirming the good conditions for preparation of the NC suspensions. Figure 1(b) also demonstrates that the particle size in the PLGA NC containing BVC was initially $147 \mathrm{~nm}$, and underwent a slight increase up to 60 days, after which the particle size was found to decrease. Similar results for polymer nanoparticle sizes have been reported in the literature..$^{50,51,53}$

Another parameter investigated was polydispersity, an index that can be indicative of stability, since it 


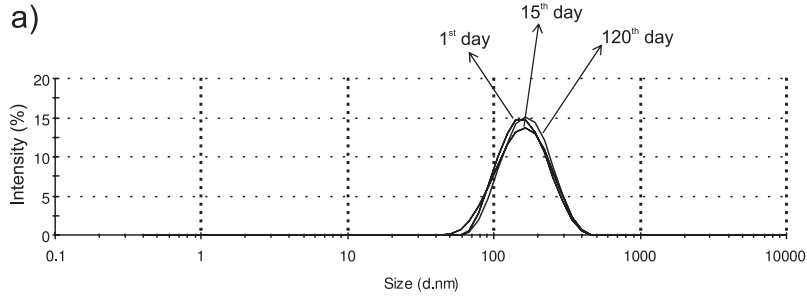

b)

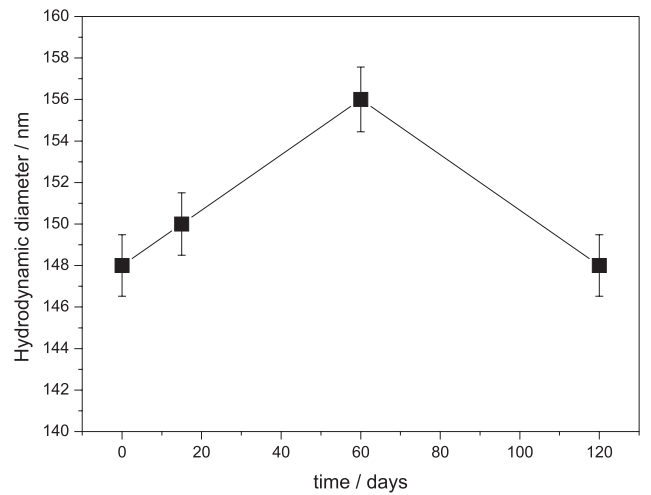

Figure 1. a) Particle size distribution (nm) by intensity (\%) of the PLGA formulation with BVC at 1,15 and 120 days; b) Particle size (nm) as a function of time $(0,15,60$ and 120 days) for PLGA NC suspensions with BVC.

represents the particle size distribution range. High polydispersity indices indicate size heterogeneity of particles in suspension, while variations in polydispersity values as a function of time indicate the formation of populations of particles with sizes that did not exist initially, possibly resulting from particle aggregation or breakdown/degradation. Polydispersity indices lower than 0.2 are ideal, because they indicate that the particle size distribution falls within a narrow range of sizes. Figure 2 shows the values of polydispersity as a function of time for the PLGA NC containing BVC.

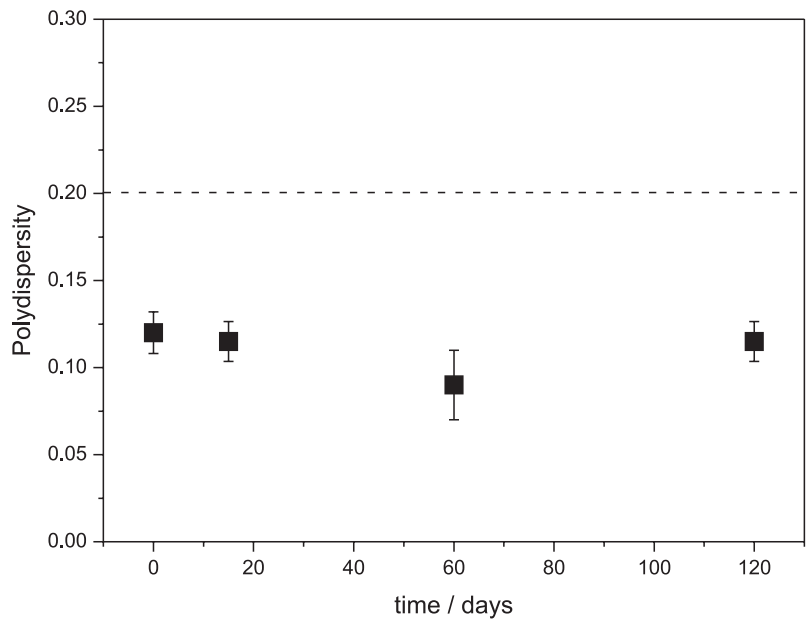

Figure 2. Polydispersity of particles as a function of time $(0,15,60$ and 120 days) for PLGA NC suspensions with BVC. The dotted line indicates the maximum value of the polydispersity index for the particle size distribution range $(0.2)$.
The polydispersity of the NC suspension with BVC did not present statistically significant differences in polydispersity index as a function of time. All the results indicated good polydispersity indices, since they were all below 0.2 .

The zeta potential, which reflects the load on the particle surface, was another parameter evaluated here. In the absence of steric mechanisms, the stability of nanoparticles is determined by the balance of repulsion and attraction forces that the particles present. Thus, high repulsion forces tend to prevent aggregation. Nanoparticles with a zeta potential of approximately $( \pm) 30$ are more stable in suspension. ${ }^{4,5}$ Figure 3 shows the zeta potential graph of the particles as a function of time.

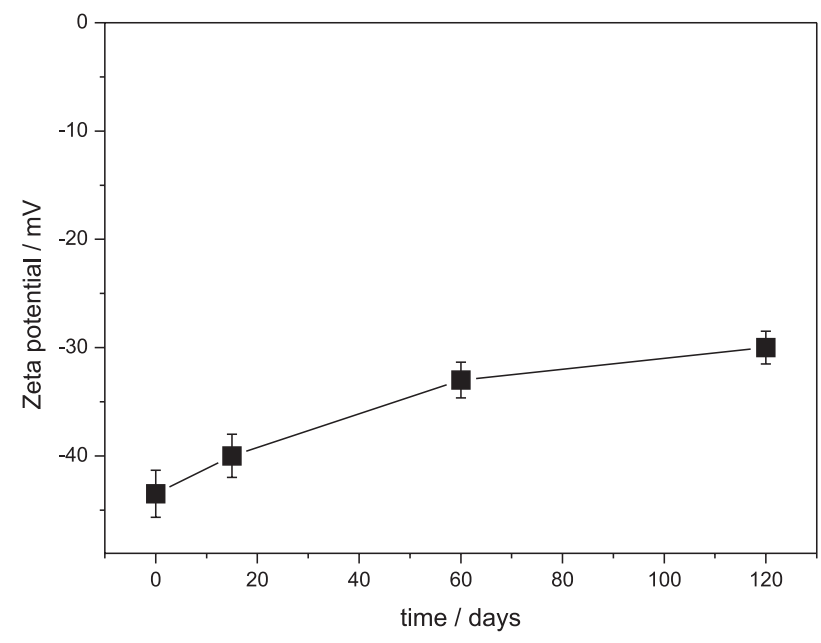

Figure 3. Zeta potential of particles as a function of time $(0,15,60$ and 120 days) for PLGA NC suspensions with BVC.

The PLGA NC suspension containing BVC showed an initial zeta potential of $-43.5 \mathrm{mV}$, which changed progressively, reaching $-30.2 \mathrm{mV}$ in 120 days (Figure 3), thus indicating the formulation's good stability. This observed change in the zeta potential could be due to a series of factors, especially changes in the interactions between pharmaceutical/polymer/surfactant at the surface of the polymeric nanocapsules. Previous published works have shown that surfactants ${ }^{54}$ and pharmaceuticals ${ }^{55}$ can modify zeta potential values in colloidal systems. However, more work is needed to better understand these changes.

The drug association rates in the nanoparticles were also evaluated as a function of time, as illustrated in Figure 4. The PLGA NC suspension with BVC showed a constant decline in the drug association rate up to 60 days, after which the rate gradually stabilizes by day 120 (Figure 4). The association rate varied from an initial $75.8 \%$ to $66.1 \%$ by day 120 . According to Müller and co-workers, ${ }^{51}$ such a decline in drug association efficiency in $\mathrm{NC}$ may be due 
to precipitation of nanocrystals of the drug during the formation of NC stabilized by surfactant agents. It was reported that these nanocrystals present the same size distribution as the NC, and therefore do not pass through the membrane used in the ultrafiltration/centrifugation procedure. Over time, these nanocrystals aggregate and precipitate, reducing the drug association rate in the NC.

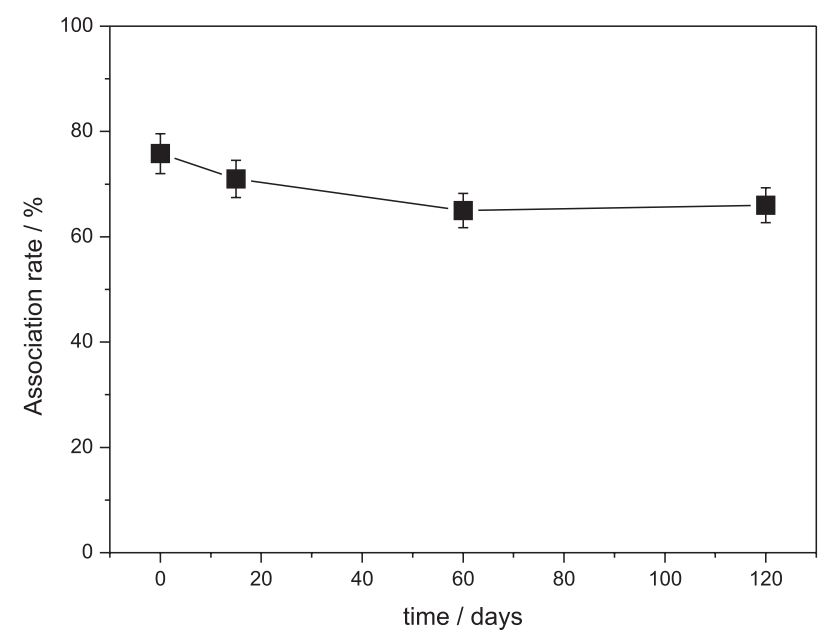

Figure 4. Association rate (\%) of the drug in the particles as a function of time $(0,15,60$ and 120 days) for PLGA NC suspensions with BVC.

Guterres et al. ${ }^{50}$ demonstrated that nanocapsules of PLA/triglycerides containing dichlofenac showed the formation of nanocrystals that were initially stabilized by surfactants, and over the time formed agglomerates, with consequent precipitation.

Another factor that could explain the reduced association rate of the BVC molecule with time, in the PLGA NC, could be its release from the NC. However, the release profile was not investigated in the present study, because it was not possible to achieve dilution sink conditions due to the quantity of BVC present in the formulation.

\section{Conclusions}

This work provided several important pieces of information about the development of formulations containing PLGA NC with BVC, based on the method of interfacial deposition of preformed polymers. The NC polymer suspensions containing this local anesthetic presented good physicochemical stability as a function of time, in terms of size, polydispersity and zeta potential, since these parameters hardly altered with time. Concerning the association rate, a reduction of the amount of BVC in the PLGA NC was observed, probably due to formation of nanocrystals of the pharmaceutical. We therefore suggest that the system of BVC associated with PLGA nanocapsules could be a useful new formulation, since BVC is a long-lasting local anesthetic.

\section{Acknowledgments}

The authors gratefully acknowledge the financial support of the Brazilian research funding agencies FAPESP (06/00121-9, 07/00127-0), CNPq and FUNDUNESP. C.M.M. was the recipient of a fellowship from FAPESP.

\section{References}

1. Rawat, M.; Singh, D.; Saraf, S.; Saraf, S. W.; Biol. Pharm. Bull. 2006, 29, 1790.

2. Anton, N.; Benoit, J. P.; Saulnier, P.; J. Control. Release 2008, $128,185$.

3. Soppimath, K. S.; Aminabhavi, T. M.; Kulkarni, A. R.; Rudzinski, W. E.; J. Control. Release 2001, 70, 1.

4. Schaffazick, S. R.; Guterres S. S.; Freitas, L. L.; Pohlmann, A. R.; Quim. Nova 2003, 26, 726.

5. Mohanraj, V. J.; Chen, Y.; Trop. J. Pharm. Res. 2006, 5, 561.

6. Nurkeeva, Z. S.; Mun, G. A.; Khutoryanskiy, V. V.; Bitekenova, A. B.; Dzhusupbekova, A. B.; J. Biomater. Sci., Polym. Ed. 2002, 13, 759 .

7. Picos, D. R.; Carril, M. G.; Mena, D. F.; Fuente, L. N.; Rev. Cubana Farm. 2000, 34, 70.

8. Durán, N.; Mattoso, L. H. C.; Morais, P. C.; Nanotecnologia: Introdução, Preparação e Caracterização de Nanomateriais e Exemplos de Aplicação, 1a. ed., Artliber: São Paulo, Brasil, 2006.

9. Nair, L. S.; Laurencin, C. T.; Prog. Polym. Sci. 2007, 32, 762.

10. Morales, M. M.; Terapias Avançadas: Células-Tronco, Terapia Gênica e Nanotecnologia Aplicada à Saúde, 1a. ed., Atheneu: São Paulo, Brasil, 2007.

11. Covino, B. G.; Vassalo, H. G.; Anestésicos Locais: Mecanismos de Ação e Uso Clínico, $1^{\text {st }}$ ed., Colina: Rio de Janeiro, 1985.

12. Collins, V. J.; Principles of Anesthesiology: General and Regional, $3^{\text {rd }}$ ed., Lea\&Febiger: New York, 1993.

13. Goodman, A. G.; Gilman, A. G.; As Bases Farmacológicas da Terapêutica, 9a. ed., McGraw-Hill: Rio de Janeiro, Brasil, 1996.

14. de Jong R. H.; Local Anesthetics, $1^{\text {st }}$ ed., C.C. Thomas: Illinois, 1994.

15. Fraceto, L. F.; de Araújo, D. R.; de Paula, E.; Quim. Nova 2008, 31,1775 .

16. Gupta, S. P.; Chem. Rev. 1991, 91, 1109.

17. de Araújo, D. R.; Fraceto, L. F.; Braga, A. F. A.; de Paula, E.; Rev. Bras. Anestesiol. 2005, 55, 316.

18. de Araújo, D. R.; Pinto, L. M. A.; Braga, A. F. A.; de Paula, E.; Rev. Bras. Anestesiol. 2003, 53, 663.

19. Simonetti, M. P. B.; Andrade, M. P.; Rev. Bras. Anestesiol. 1996, 46,35 . 
20. Oliveira, A. G.; Scarpa, M. V.; Correa, M. A.; Cera, L. F. R.; Formariz, T. P.; Quim. Nova 2004, 27, 131.

21. Dollo, G.; Le Corre, P.; Chevanne, F.; Le Verge, R.; Int. J. Pharm. 1996, 136, 165.

22. de Araújo, D. R.; Braga, A. F. A.; Moraes, C. M.; Fraceto, L. F.; de Paula, E.; Rev. Bras. Anestesiol. 2006, 56, 495.

23. Araújo, D. R.; Tsuneda, S. S.; Cereda, C. M. S.; Carvalho, F. G. F.; Preté, P. S. C; Fernandes, S. A.; Yokaichiya, F.; Franco, M. K. K. D.; Mazzaro, I.; Fraceto, L. F.; Braga, A. F. A.; de Paula, E.; Eur. J. Pharm. Sci. 2008, 33, 60.

24. Moraes, C. M.; Abrami, P.; Araújo, D. R.; Braga, A. F. A.; Issa, M. G.; Ferraz, H. G.; de Paula, E.; Fraceto, L. F.; J. Inclusion Phenom. Macrocyclic Chem. 2007, 57, 313.

25. Moraes, C. M.; Abrami, P.; de Paula, E.; Braga, A. F.; Fraceto, L. F.; Int. J. Pharm. 2007, 331, 99.

26. Moraes, C. M.; Abrami, P.; de Paula, E.; Andreo-Filho, N.; Fraceto, L. F.; Quim. Nova 2007, 30, 777.

27. Irie, T.; Uekama, K.; Pharm. Sci. 1997, 86, 147.

28. Loftsson, T.; Masson, M.; Int. J. Pharm. 2001, 225, 15.

29. Pinto, L. M.; Fraceto, L. F.; Santana, M. H. A.; Pertinhez, T. A.; Junior, S. O.; de Paula, E.; J. Pharm. Biomed. Anal. 2005, 39, 956.

30. Kuzma, P. J.; Kline, M. D.; Calkins, M. D.; Staats, P. S.; Reg. Anesth. Pain Med. 1997, 22, 543.

31. Fraceto, L. F.; Pinto, L. M. A., Franzoni, L.; Braga, A. C.; Spisni, A.; Schreier, S.; de Paula, E.; Biophys. Chem. 2002, 99, 229.

32. de Araújo, D. R.; Cereda, C. M. S.; Brunetto, G. B.; Pinto, L. M. A.; Santana, M. H. A.; de Paula, E.; Can. J. Anesth. 2004, $51,566$.

33. Cereda, C. M. S.; de Araújo, D. R.; Brunetto, G. B.; de Paula, E.; J. Pharm. Pharmacol. 2004, 7, 235.

34. Cereda, C. M. S.; Bruschini, G.; De Araújo, D. R.; de Paula, E.; Reg. Anesth. Pain Med. 2006, 53, 1092.

35. Cereda, C. M. S.; Tófoli, G. R.; De Araújo, D. R.; Arana, S., de Paula, E.; Reg. Anesth. Pain Med. 2008, 33, 62.

36. Araújo, D. R.; Cereda, C. M. S.; Brunetto, G. B.; Vomero, V. U.; Pierucci, A.; Santo Neto, H.; De Oliveira, A. L. R.; Fraceto, L. F.; Braga, A. F. A.; De Paula, E.; J. Pharm. Pharmacol. 2008, $60,1449$.
37. Colombo, G.; Padera, R.; Langer, R.; Kohane, D. S.; J. Biomed. Mater. Res., Part A 2005, 75, 458.

38. Grant, G. J.; Bansinath, M.; Reg. Anesth. Pain Med. 2001, 26, 61.

39. Grant, S. A.; Best Pract. Res. Clin. Anaesth. 2002, 16, 345.

40. Le Guévello, P.; Le Corre, P.; Chevanne, F.; Le Verge, R.; J. Chromatogr. 1993, 622, 284.

41. Rose, J. S.; Neal, J. M.; Kopacz, D. J.; Reg. Anesth. Pain Med. 2005, 30, 275.

42. Kranz, H.; Bodmeier, R.; Eur. J. Pharm. Sci. 2008, 34, 164.

43. Holgado, M. A.; Arias, J. L.; Cózar, M. J.; Alvarez-Fuentes, J.; Ganan-Calvo, A. M.; Fernandez-Arevalo, M.; Int. J. Pharm. 2008, 358, 27.

44. Gorner, T.; Gref, R.; Michenot, D.; Sommer, F.; Tran, M. N.; Dellacherie, E.; J. Control. Release 1999, 57, 259.

45. Govender, T.; Stolnik, S.; Garnett, M. C.; Illum, L.; Davis, S. S.; J. Control. Release 1999, 57, 171.

46. Govender, T.; Riley, T.; Ehtezazi, T.; Garnett, M. C.; Stolnik, S.; Illum, L.; Davis, S. S.; Int. J. Pharm. 2000, 199, 95.

47. Polakovic, M.; Gorner, T.; Gref , R.; Dellacherie, E.; J. Control. Release 1999, 60, 169.

48. Moraes, C. M.; de Matos, A. P.; de Paula, E.; Rosa, A. H.; Fraceto, L. F.; Mater. Sci. Eng., B 2009, 165, 243.

49. Fessi, H., Puiseiux, F.; Devissaguet, J-P.; Ammoury, N.; Benita, S.; Int. J. Pharm. 1989, 55, 1.

50. Guterres, S. S.; Fessi, H.; Barratt, G.; Devissaguet, J. P.; Puisieux, F.; Int. J. Pharm. 1995, 113, 57.

51. Muller, C. R.; Haas, S. E.; Bassani, V. L.; Gutterres, S. S.; Fessi, H.; Peralba, M. C. R.; Pohlmann, A. R.; Quim. Nova 2004, 27, 555.

52. Couvreur, P.; Barratt, G.; Fattal, E.; Legrand, P.; Vauthier, C.; Crit. Rev. Ther. Drug Carrier Syst. 2002, 19, 99.

53. Pohlmann, A. R.; Weiss, V.; Mertins, O.; Silveira, N. P.; Guterres, S. S.; Eur. J. Pharm. Sci. 2002, 16, 305.

54. Hsu, J. Y.; Nacu, A.; J. Coll. Interf. Sci. 2003, 259, 374.

55. Hsu, J. P.; Lee, H. Y.; Guan, Y. S.; Kim, J. C.; J. Ind. Eng. Chem. 2008, 14, 608.

Received: June 17, 2009

Web Release Date: February 1, 2010

FAPESP helped in meeting the publication costs of this article. 